\title{
Estimation of Aedes aegypti (Diptera: Culicidae) population size and adult male survival in an urban area in Panama
}

\author{
Marco Neira ${ }^{1 /+}$, Renaud Lacroix ${ }^{1}$, Lorenzo Cáceres ${ }^{2}$, Paul E Kaiser ${ }^{1}$, Josue Young ${ }^{2}$, Lleysa Pineda ${ }^{2}$, \\ Isaac Black', Nestor Sosa ${ }^{2}$, Derric Nimmo', Luke Alphey', Andrew McKemey ${ }^{1}$ \\ ${ }^{1}$ Oxitec Ltd, Oxford, UK ${ }^{2}$ Gorgas Memorial Institute for Health Studies, Panama City, Panama
}

Traditional mosquito control strategies rely heavily on the use of chemical insecticides. However, concerns about the efficiency of traditional control methods, environmental impact and emerging pesticide resistance have highlighted the necessity for developing innovative tools for mosquito control. Some novel strategies, including release of insects carrying a dominant lethal gene $\left(R I D L^{\circledR}\right)$, rely on the sustained release of modified male mosquitoes and therefore benefit from a thorough understanding of the biology of the male of the species. In this report we present the results of a mark-release-recapture study aimed at: (i) establishing the survival in the field of laboratory-reared, wild-type male Aedes aegypti and (b) estimating the size of the local adult Ae. aegypti population. The study took place in Panama, a country where recent increases in the incidence and severity of dengue cases have prompted health authorities to evaluate alternative strategies for vector control. Results suggest a life expectancy of 2.3 days for released male mosquitoes (confidence interval: 1.78-2.86). Overall, the male mosquito population was estimated at 58 males/ha (range 12-81 males/ha), which can be extrapolated to an average of 0.64 pupae/person for the study area. The practical implications of these results are discussed.

Key words: Aedes aegypti - daily survival - male mosquito - mark-release-recapture - Panama - population estimation

Dengue fever is the most important arthropod-borne viral disease in humans, with approximately 390 million new infections estimated to occur yearly (WHO/TDR 2006, 2009, Bhatt et al. 2013). The disease is caused by infection with one of four serotypes of the dengue virus (DENV) and is mainly transmitted by the mosquito $\mathrm{Ae}$ des aegypti, a species of African origin which is highly anthropophilic and mostly active during daylight hours (Christophers 1960).

First introduced to the Americas during colonial times, Ae. aegypti was nearly eradicated from the continent thanks to extensive control efforts during the 1950's and 1960's which relied heavily on the use of chemicals, particularly DDT (Camargo 1967). Unfortunately, countries that did not achieve eradication during this period served as sources for re-infestation and during the following decades Ae. aegypti re-invaded every country from which it was once eradicated. Currently, Ae. aegypti is reported to exist in all Latin-American countries, with the exception of continental Chile (Vasconcelos et al. 1999).

In Panama, dengue has become a public health problem of increasing relevance in recent years, prompting Panamanian health officials to evaluate alternative strategies, including release of insects carrying a dominant lethal gene (RIDL ${ }^{\circledR}$ ) for vector control. Following the re-establishment of Ae. aegypti in this country in 1985, there have

doi: $10.1590 / 0074-0276140136$

$\mathrm{MN}$ and RL contributed equally to this work.

+ Corresponding author: mvneira@puce.edu.ec

Received 18 April 2014

Accepted 11 July 2014 been more than 43,000 dengue cases reported up to date, including over 100 severe cases and 32 fatalities (Cáceres et al. 2013). Factors contributing to this situation include elevated infestation indexes and co-circulation of all four dengue serotypes in the region. Although recent reports suggest that Panamanian populations of Ae. aegypti are for the most part susceptible to commercial pesticides, the same reports have uncovered the existence of vector populations displaying moderate levels of resistance to deltamethrin in the country, indicating the potential for future dissemination of these resistant genotypes if control programs are not carefully managed (Cáceres et al. 2013).

Because no commercial vaccine or specific treatment against the DENV is currently available (Halstead 2012, Sabchareon et al. 2012), vector control remains the principal mechanism for dengue control and prevention. Unfortunately, successful campaigns to control $A e$. aegypti have proven difficult and expensive to sustain. Furthermore, chemical insecticides, still a central component of most vector control programmes, are threatened both by the emergence of pesticide resistance in mosquito populations and by increasing concerns about environmental impact. These various limitations of current methods highlight the need for the development of new tools for mosquito control.

Strategies based on the genetic control of insect populations represent promising new tools for the control of disease vectors (Alphey et al. 2008, 2010). One such strategy, known as RIDL ${ }^{\circledR}$ (Thomas et al. 2000, Phuc et al. 2007), has recently been used to successfully suppress a field population of Ae. aegypti (Harris et al. 2012), supporting the notion that genetically modified organisms can indeed be used as effective tools in the fight against mosquito-borne disease. 
Release of female mosquitoes is seen as undesirable, as female mosquitoes will tend to bite even if sterile or otherwise modified. Furthermore, for sterile-male methods, co-release of sterile females may lead to the sterile males courting the sterile females, which thereby "distract" them from seeking out wild females (Rendon et al. 2004, Papathanos et al. 2009). Therefore, RIDL ${ }^{\circledR}$ strategies for genetic vector control rely on the release of substantially male-only populations of mosquitoes, which cannot bite (and therefore transmit diseases). Unfortunately, most research regarding the biology and ecology of Ae. aegypti has been focused on females due to their role in disease transmission, leaving large gaps in our knowledge of the biology of male mosquitoes.

Here we report a mark-release-recapture (MRR) experiment aimed at establishing the survival in the field of wild-type male Ae. aegypti reared under laboratory conditions. In addition, the results of this experiment allowed us to estimate the size of the local adult Ae. aegypti population in relation to the human population in the Panamanian neighbourhood where the study was conducted.

\section{MATERIALS AND METHODS}

Study area - The study was conducted in the community of Nuevo Chorrillo, located approximately $17 \mathrm{~km}$ west of Panama City, at 8 $8^{\circ} 57^{\prime} 10.97^{\prime \prime} \mathrm{N} 79^{\circ} 41^{\prime} 50.57^{\prime \prime} \mathrm{W}, 71$ $\mathrm{m}$ altitude (Fig. 1). Nuevo Chorrillo belongs to the township of Nuevo Emperador, which is a sub-division of the Arraijan district, Panama province. This area experienced a large dengue outbreak in 2009, with 1,340 cases reported (population in the Arraijan district was estimated at 220,779 inhabitants in a 2010 national census) (arraijan.municipios.gob.pa/index.php/sobre-el-distrito/ poblacion). Subsequently, the number of reported dengue cases in the district for 2010 and 2011 was 37 and 174, respectively (L Diez, Nuevo Chorrillo Community Health Centre, unpublished observations).

The population of Nuevo Chorrillo is estimated at 4,722 inhabitants living in 1,042 houses (L Diez, Nuevo Chorrillo Community Health Centre, unpublished observations), which gives an average density of $\sim 4.5$ persons per house. The study area encompassed a section of 0.1 $\mathrm{Km}^{2}$ (10 ha) located towards the southwestern end of the town (Fig. 1) and contained 249 houses, for an estimated population of 1,121 persons, which in turn is equivalent to $\sim 11,000$ persons $/ \mathrm{Km}^{2}$ ( 112 persons/ha). Temperature in the area fluctuates between $26-28^{\circ} \mathrm{C}$ throughout the year. Rainfall is highest between May-December (average $228 \mathrm{~mm} / \mathrm{month}$ ) and lowest between January-April (average $39 \mathrm{~mm} / \mathrm{month}$ ) (The Panama Canal Port Authority, unpublished observations).

Mosquito strain, rearing and marking - The study was performed using a Panamanian strain of Ae. aegypti originally collected in March 2010 at the 24 de Diciembre community (municipality of Panama). The strain had been continuously maintained at the Gorgas Institute's insectaries until used for this trial, undergoing re-hatch cycles approximately every four months.

Mosquito rearing was performed in dedicated insectaries located at the Gorgas Institute's campus in Panama City. Eggs were hatched en masse by placing them in wa-
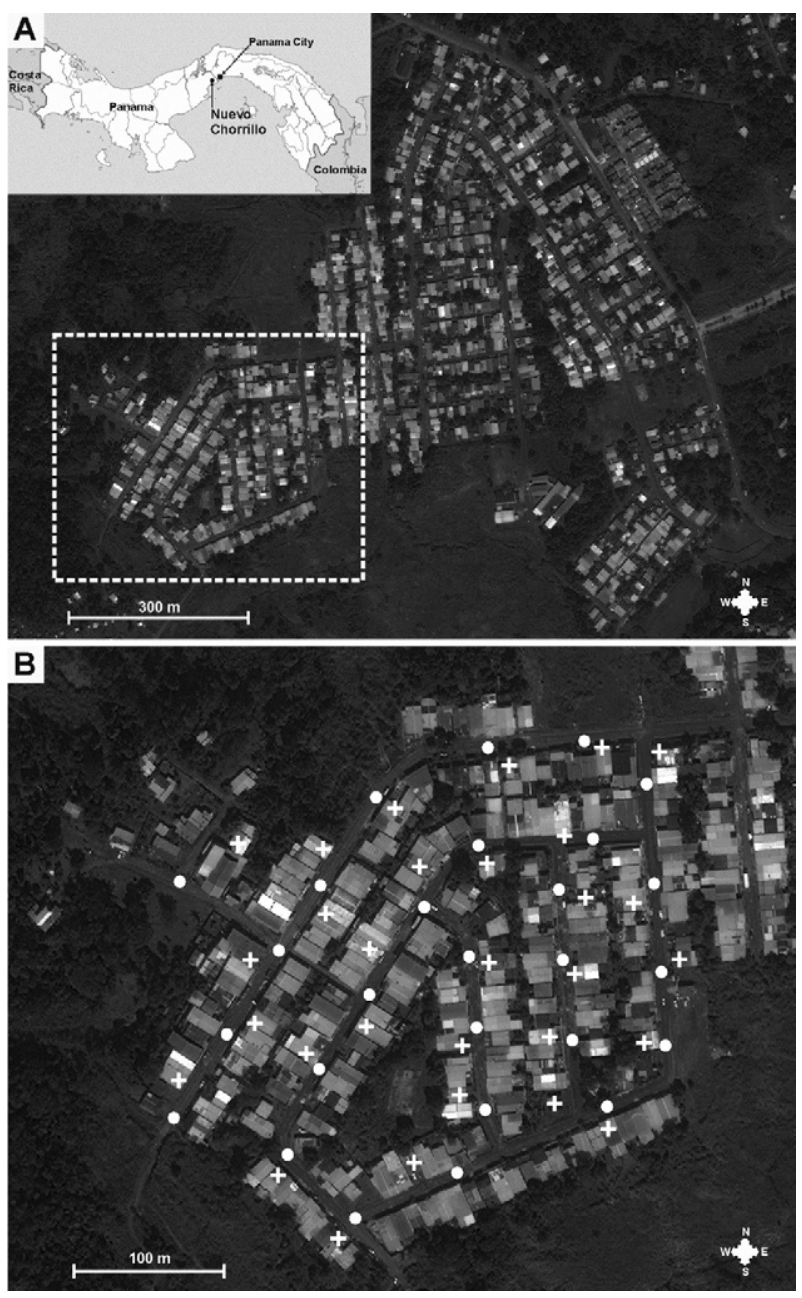

Fig. 1: study area. A: community of Nuevo Chorrillo. Inset map shows the approximate location of Nuevo Chorrillo in relation to Panama's capital, Panama City. Dashed square shows the limits of the southwestern section, where the study was conducted; B: location of release points (white circles) and BG-Sentinel traps (white crosses) in the study area. Panel A inset modified from upload.wikimedia.org/ wikipedia/commons/4/4e/Panama_location_map.svg. Original figure under the Creative Commons Attribution-ShareAlike 3.0 Unported license (creativecommons.org/licenses/by-sa/3.0/deed.en). Satellite images in panel A and B: @DigitalGlobe 2012, used with permission.

ter and under vacuum for $1 \mathrm{~h}$. First instar larvae were aliquoted in plastic trays $(29 \times 23 \times 6 \mathrm{~cm})$ and reared under standard insectary conditions (temperature: $28^{\circ} \mathrm{C} \pm 2^{\circ} \mathrm{C}$; humidity: $80 \% \pm 10 \%$ ) and a photoperiod of $12 \mathrm{~h}$ light: 12 $\mathrm{h}$ darkness. Larvae were fed ground TetraMin ${ }^{\circledR}$ flakes (Tetra GmbH, Germany) daily. Upon pupation, male and female pupae were mechanically sorted by size (Ansari et al. 1977, Focks 1980). Male pupae were recovered and a sample of 1,620 of these specimens was used to verify the quality of the mechanised sexing procedure by individually sexing each pupa under a dissection microscope. Only one female pupa was found in the sample $(0.06 \%$ of the total), implying a sorting efficiency of $99.94 \%$ [exact binomial 95\% confidence interval (CI): 100-99.66\%]. Female pupae were killed by freezing overnight at $-20^{\circ} \mathrm{C}$. 
Male pupae were immediately aliquoted (on average 540 pupae per container) in $100 \mathrm{~mL}$ plastic weight boats (Ramboldi Ltd, Cyprus) placed inside 1.8-L clear plastic cylindrical containers (Produtos Prafesta ${ }^{\circledR}$, Brazil) which had their inner walls previously coated with DayGlo $^{\circledR}$ "Red Rocket" fluorescent powder (Day-Glo Color Corporation, USA). A round hole was cut-off the lid of each container and covered with a sheet of fine mesh, to allow for air flow and provide a surface for sugar feeding. A sheet of damp cotton wool was placed on top of each container to avoid desiccation.

After emerging, adult mosquitoes moved around and came in contact with the fluorescent powder in the walls of the container, which stuck to the surface of their bodies and resulted in clear and even marking of the specimens. This procedure efficiently marked all mosquitoes with no obvious adverse effects (A McKemey, unpublished observations). A $10 \%$ sucrose solution was provided ad libitum to adult males until their release. All adults had emerged $48 \mathrm{~h}$ after sex sorting of pupae. Water was drained from the plastic containers through a small incision and adult males were held for a further $48 \mathrm{~h}$ to allow them to reach sexual maturity prior to release.

Mosquito release and recapture - On the day of release, plastic containers holding adult mosquitoes were loaded in a large cooler box (to avoid overheating) and transported to the field site in the back of a pick-up truck. The release took place between 10:00 am-11:00 am. At each one of the 27 pre-selected release spots (Fig. 1), one container was opened and mosquitoes were allowed to fly away. Following release, a sample of eight containers were re-fitted with their respective lids and taken back to the laboratory, where the numbers of dead and nonreleased specimens were counted and used to estimate the number of released males.

To recapture released mosquitoes, 30 BG-Sentinel traps baited with BG-lures (Biogents, Germany) and powered by rechargeable $9 \mathrm{Ah} / 12$-volt batteries (model CP1290, Vision Group, China) were distributed around the study area (Fig. 1). On the day of release, all traps were activated before any males were released. Traps were thereafter visited every $24 \mathrm{~h}$. During each visit, batteries were replaced with fully charged units and captured mosquitoes were collected and taken to the laboratories at the Gorgas Institute, where they were sorted and screened. Ae. aegypti specimens were checked for the presence of fluorescent powder by examining them under a UVR 9000 hand-held ultraviolet UV light source (Bayco, USA).

Wing measurement - For each selected specimen, one wing was carefully removed and mounted on a microscope slide. Digital micrographs of mounted wings were obtained using a Leica MZ 125 stereoscope fitted with a Leica DFC 500 digital camera (Leica Microsystems, Germany).

Wing length was measured using the ImageJ software package (Schneider et al. 2012). Wing length was defined as the linear distance from the axillary incision to the apical margin, excluding the fringe (Harbach \& Knight 1980, Maciel-de-Freitas et al. 2007).

Data analysis - Statistical analyses were performed using R software, an open source language and environment for statistical computing (R Core Team, Austria). Daily survival probability (DSP) of released males in the field was estimated via a non-linear method (nonlinear least square function) (Buonaccorsi et al. 2003); life expectancy (LE) was derived from the estimated survival using the formula $-1 / \log _{\mathrm{e}}$ (DSP) (Niebylski \& Craig Jr 1994). Population size was estimated using the Petersen-Lincoln test (Petersen 1896, Lincoln 1930). The number of pupae per person was determined from the wild mosquito population estimates following the calculations described by Focks et al. (2000). 95\% CI for survival and population estimates were calculated by bootstrap analysis (1,000 repeats).

Wing length groups were tested for normality by Shapiro-Wilk test and then differences between groups were tested using Student $t$ test (normal distribution) or Kolmogorov-Smirnov test (non-normal distribution). Linear relation between day of recapture and size was tested by ANOVA.

Ethics - Since this research work did not involve any human or other vertebrate subjects, and upon consultation with Panamanian health authorities (Gorgas Memorial Institute for Health Studies), it was established that no ethical review was required for the study to proceed.

\section{RESULTS}

Release and recapture numbers - An estimated 14,388 adult male marked mosquitoes were released on 11 November 2011 (average of 533 males/release point). Trapping started the day of release and continued until 24 November 2011, which marked the end of three consecutive days without recaptures. Over the 13-day trapping period, $4.43 \%(637 / 14,388)$ of released males were recaptured. Nineteen wild male and 246 wild female $A e$. aegypti were caught in the traps during the study, equivalent to a 0.08 sex ratio in the area, given an assumption of similar attractiveness of the traps to both sexes (Kröckel et al. 2006, Maciel-de-Freitas et al. 2006, Williams et al. 2006). A total of 305 Culex specimens were also caught, but were not identified to species level.

Longevity - The DSP was 0.14 (CI: 0.11-0.18), equivalent to an LE of 0.5 days (CI: $0.46-0.58)$. However, the data did not respect the assumption of normal distribution (Shapiro-Wilk normality test: $p=0.003$ ) which invalidates the DSP estimate; this is likely the result of the number of recaptures on day 1 , which was much higher than during the other days combined (503 vs. 134). Consequently, calculations were run again after removing day 1 recaptures, resulting in a DSP of 0.65 (CI: $0.57-$ 0.70 ; Shapiro-Wilk normality test: $\mathrm{p}=0.24)$, equivalent to an LE of 2.3 days (CI: $1.78 ; 2.86$ ).

Wild population estimation - The wild population was calculated for days 1,2 and 3, as well as their average (Table). To estimate the number of released males remaining in the area on different days, we used the DSP value estimated excluding day 1 recaptures $(0.65)$. The population estimations were 111, 773 and 328 males for days 1, 2 and 3 respectively, with an average of 404 males, i.e., 43 males/ha or 0.36 males/person.

The male:female sex ratio observed among captured specimens in this study (0.08) is extremely low in comparison to other reports, which usually place this value between 0.5-1 when BG-traps are used [Maciel-de-Frei- 
TABLE

Daily and average wild population and pupae/person estimation

\begin{tabular}{lcc}
\hline Day & $\begin{array}{c}\text { Wild population } \\
\text { males }(\mathrm{CI})\end{array}$ & $\begin{array}{c}\text { Pupae/person } \\
0.7: 1 \text { sex ratio }(\mathrm{CI})\end{array}$ \\
\hline 1 & $111(36.8-206.2)$ & $0.13(0.04-0.24)$ \\
2 & $773(238-1772.8)$ & $0.9(0.28-2.1)$ \\
3 & $328(0-714.6)$ & $0.38(0-0.83)$ \\
Average & 404 & 0.47 \\
Average & 550 & 0.64 \\
(2 and 3 combined) & &
\end{tabular}

the wild population density was estimated from day 1, 2 and 3 recaptures separately and combined for day 2 and 3 (Petersen 1896, Lincoln 1930). The confidence interval (CI) calculated by bootstrap using 1,000 repeats is also presented. The equivalent pupae/person estimates shown use a male:female sex ratio of $0.7: 1$ in the calculations (Focks et al. 2000).

tas et al. (2006), Barrera et al. (2011), Harris et al. (2012) and our unpublished observations] and has been reported to reach values as high as 1.4 (Williams et al. 2006) and as low as 0.3 (Kröckel et al. 2006). The reasons behind the unusually low figure obtained in the present study remain to be determined. For calculations, we will consider a more realistic sex ratio of 0.7 [representing an average of male:female ratios reported by Kröckel et al. (2006), Maciel-de-Freitas et al. (2006), Williams et al. (2006), Barrera et al. (2011) and Harris et al. (2012)]. Assuming similar recapture of males and females, the density of females in the area can be estimated at 83 females/ha or 0.7 females/person. Therefore, we could estimate the number of pupae per person (Table). The pupal development time chosen was two days, the proportion of pupae successfully emerging as adults 0.83 and the DSP of wild-type males 0.8 (Focks et al. 2000). On average the pupae/person ratio was 0.64 ; taking each day separately, the two estimates were 0.38 (CI: $0-0.83$ ) and 0.9 (CI: $0.28-2.10$ ) for day 2 data.

Wing length - Wing size, an indicator of body size (Nasci 1990, Ponlawat \& Harrington 2007), was measured for a sample of 50 marked male mosquitoes randomly selected before release, 190 recaptured (marked) male mosquitoes and 10 wild (non-marked) captured male mosquitoes (Fig. 2) (the 9 remaining wild mosquitoes were too damaged to use for this purpose). The average ( \pm standard error of the mean) wing lengths of the analysed groups were as follows: released males $=2.86$ $\mathrm{mm}( \pm 0.019)$, recaptured males $=2.87 \mathrm{~mm}( \pm 0.006)$, wild males $=2.61 \mathrm{~mm}( \pm 0.069)$. The average wing length of marked recaptured males was not significantly different from that of released males $(p=0.96)$, indicating that size did not affect the probability of recapture. Both released and recaptured males were significantly larger than wild males $(p=0.0002$ and $p=0.0006$, respectively). There was no linear relation between day of recapture and size of the males (linear regression: $\mathrm{p}=$ 0.92 , data not shown).

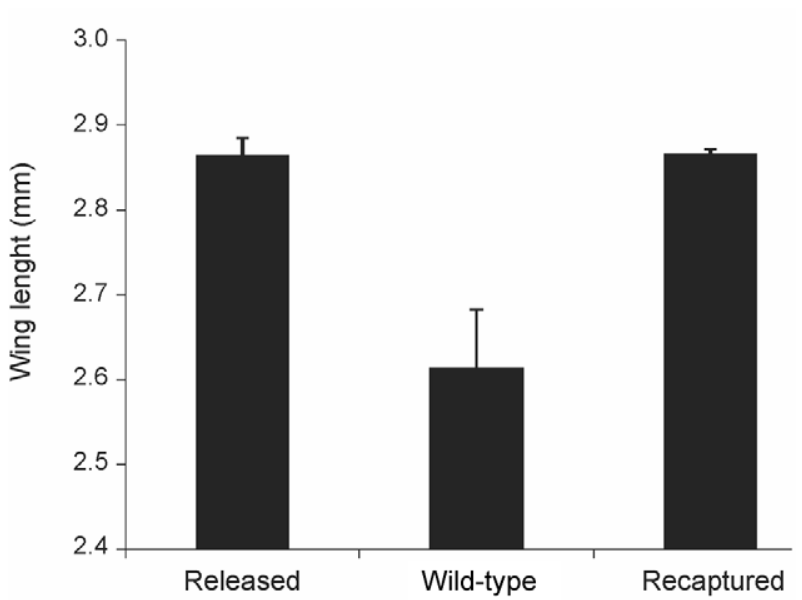

Fig. 2: size of the released, wild-type and recaptured males. The size of the released males $(n=50)$, recaptured males $(n=190)$ and wild type males $(n=10)$ was assessed by measuring their wing length $(\mathrm{mm})$. Wild-type males were significantly smaller than both released males (Kolmogorov-Smirnov test: $\mathrm{p}=0.0006$ ) and recaptured males (Kolmogorov-Smirnov test: $\mathrm{p}=0.0002$ ). There was no difference between released and recaptured males (Student $t$ test: $\mathrm{p}=0.96$ ).

\section{DISCUSSION}

This study adds to the relatively sparse information available on survival and wild population of male $A e$. aegypti, which is critical to designing successful genetic control programmes. Although various population-monitoring tools can provide indirect measures of the size of specific mosquito populations or their relative change over time, estimating the absolute size of a wild mosquito population is best accomplished using pupal surveys which are expensive, time consuming and dependent on personnel's ability (Focks \& Chadee 1997) or MRR experiments.

Though many mathematical methods have been developed to support these field studies, there is unfortunately no consensus as to what the most appropriate methodology is for population size estimation. Deterministic population estimation models are based on a dilution effect observed from MRR experiments and involve single release/single capture [Petersen-Lincoln method (Petersen 1896, Lincoln 1930)], single release/ multiple captures [Yamamura method (Yamamura et al. 1992), Jackson Positive method (Jackson 1939)], multiple releases/single captures [Jackson Negative method (Jackson 1939)] or multiple releases/multiple captures [Fisher and Ford's method (Fisher \& Ford 1947), Bailey's triple catch method (Bailey 1951, 1952)]. Stochastic models involving multiple releases/multiple captures have also been developed (Jolly 1965, Seber 1965, Manly \& Parr 1968). Recent studies have used the shift in the sex ratio of captures after releases of Wolbacchia infected Ae. aegypti females to estimate the wild population of females (Ritchie et al. 2013). This study was designed to include a single multi-point massive release from laboratory reared males without background monitoring. Consequently, the Petersen-Lincoln index was used as an estimator of mosquito population and the estimated survival rate for the calculation of the number of survivors on each day (similar to the Yamamura method). 
Population estimation methods use several assumptions (Dyck et al. 2005) which are not always respected or explicitly assessed: (i) closed population, (ii) all individuals have the same probability of capture, (iii) marking individuals does not affect their capabilities and behaviour, (iv) animals do not lose their marking and (v) all marked individuals are reported. Fluorescent powder marking is widely used in mosquito MRR and is considered not to interfere with assumptions ii, iv and $\mathrm{v}$ when applied correctly (Hagler \& Jackson 2001); preliminary tests were performed to ensure that the marking did not affect mortality of the mosquitoes.

Due to the limited range of dispersal typical of male Ae. aegypti (Muir \& Kay 1998, Maciel-de-Freitas et al. 2007, Lacroix et al. 2012) and the virtual absence of human dwellings immediately to the north, south and west of the study area (Fig. 1), it was assumed that immigration and emigration were limited to the $150 \mathrm{~m}$ to the east of the study area and should balance each other, as should the proportions of marked and wild males emigrating. As the study was conducted at the end of the rainy season, the population should have been stable-emergence and mortality of adults were assumed to be equivalent. Traps were assumed to have equal attractiveness to released and wild males.

Estimations of DSP make the assumption of equal probability of recapture over time. Similarly, MRR statistics assume equal probability of recapture of marked/ released and unmarked (wild) mosquitoes. However, behaviour associated with release (altered flight activity/search for mates, resting sites etc.) could affect probability of recapture on the release day compared to wild mosquitoes and to subsequent recapture days. It was considered that after the first $24 \mathrm{~h}$, subsequent activity and behaviour of released males resulting in contact with traps and probability of recapture were comparable to that of wild males; thus only estimates not including recapture data for day 1 will be discussed further.

Overall, the male population was estimated at 58 males/ha (range 12-81 males/ha), which falls in the low range of the estimates from a study in Kenya, where 37107 males/ha were reported (Trpis \& Häusermann 1986). In a different study by Focks et al. (1981) the local male population of a study area in New Orleans (United States of America) was estimated by pupae survey to be between 264-558 males, depending on DSP (Focks et al. 1981). Although the area surveyed in that study is not stated clearly in the report, we estimated around 5 ha (using the cars visible in the report's aerial photo as a scale), which would correspond to a density of 53-111 males/ha. Much higher male population estimates ( $>1,700$ males/ ha) have been reported from tyre dumps in Delhi, India (Conway et al. 1974). However, such tire dumps may represent unusually good larval sites for Ae. aegypti, leading to unusually high population densities. We anticipated that the released males would show different behaviour right after release that would likely affect their survival. Supporting this hypothesis, we found that incorporating data from day 1 in the DSP calculation led to an estimated DSP of 0.14 (95\% CI: 0.11-0.18), equivalent to 0.51 days LE. This low value would imply that all the released males would have died by day 5 , yet we were able to recapture marked specimens until day 10 (Fig. 3).

The full recapture data did not conform to the normality distribution necessary to the estimation of the DSP, however, as DSP is assumed constant it can also be estimated if one day is excluded from the data. In this study, day 1 recaptures were much higher than other days and likely biased the DSP estimates. Using data only from day 2 onwards gave a calculated DSP of 0.65 (95\% CI: 0.57-0.71) (equivalent to 2.3 days LE) where, theoretically, the last male would die around day 22 . Additionally, the model's sensitivity to the number of males released is low [DSP estimate is still 0.65 if only 6,000 males $(<50 \%$ of total released) are assumed to remain on day 2]. This DSP value is similar to those reported previously in studies that used either laboratory or recently colonised males, where DSP values range from 0.48-0.85 (Sheppard et al. 1969, Trpis \& Häusermann 1986, Muir \& Kay 1998, Valerio et al. 2012).

Focks and Chadee (1997) proposed that the estimation of populations by performing pupal surveys and relating them to the local human population (effectively measuring the number of pupae per person in the area of interest) is a more accurate method than traditional $\mathrm{Ae}$ des indexes. During a multi-country pupae survey project that applied this concept in the Americas, Caribbean, Africa and Asia, the reported mosquito densities ranged from 0.02-7.63 pupae/person, with most values falling between 0.5-1.5 (Focks \& Alexander 2006). In our study, the estimated population is equivalent to 0.64 pupae/person on average, a value that falls in the typical range reported by Focks and Alexander (2006). Many mosquito populations undergo seasonal fluctuation; our study was performed at the end of the rainy season, when the population might be expected to be at or near its peak.

The recapture rate in our study $(4.4 \% ; 0.93 \%$ without day 1) was lower than the $7.4 \%$ and $12.3 \%$ reported in Brazil using BG-Sentinel traps (Maciel-de-Freitas et al. 2007 ) and in the low range of values reported by studies that used other trapping tools: $6.6 \%$ and $11.5 \%$ (Reuben et al. 1973), 23\% (Trpis \& Häusermann 1986), $4.6 \%$ and $14.8 \%$ (Muir \& Kay 1998), 17\% (Harrington et al. 2005) and $2.1-7.8 \%$ (Valerio et al. 2012). Recapture rates for BG-Sentinel traps vary between areas depending, at least in part, on the density of human populations that compete with the traps to attract mosquitoes. Indeed, the recapture rates of marked males in an uninhabited area $(17.2 \%$ and $50.2 \%$ ) were in the highest range of the literature (Lacroix et al. 2012). Therefore, the relatively high human density found in our study site ( 112 persons/ha) might explain, at least in part, the low recapture rates observed.

The average wing lengths of the released and recaptured males were not significantly different, so there was no indication of a size effect in recapture probability of individuals. Additionally, although bigger males have been reported to survive longer (Maciel-de-Freitas et al. 2007), our study showed no significant correlation between wing size and day of recapture. However, it is possible that this lack of correlation is an artefact caused by the small numbers of specimens recaptured during the later days and differences could be revealed with larger samples or multiple studies. 


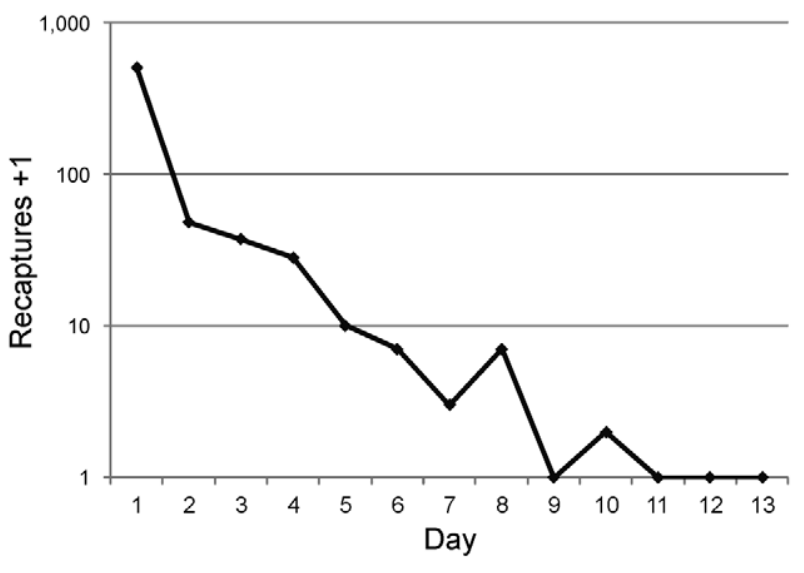

Fig. 3: male recaptures over time. Daily recaptures are presented on a logarithmic scale for the 13 day trapping period of the study.

Insectary-reared released males were significantly larger than their wild counterparts, an effect that has been observed in previous studies (Johnson et al. 2012, Valerio et al. 2012). This may reflect the different larval environments of each group: while insectary-reared specimens are maintained in relatively uniform conditions intended to be reasonably nurturing, the harsher breeding environment faced by wild specimens (i.e. variations in food availability, temperature and specimen density) may explain the relatively small size of wild specimens.

It is worth mentioning that although the strain used for release was originally collected within the municipality of Panama, it had been reared for approximately 20 months under insectary conditions prior to its use in the current experiment (roughly equivalent to 5 generations, since the strain was re-hatched every 4 months). Although the strain did not undergo any kind of purposeful selection during this time, it is nonetheless possible that released specimens presented slight genetic variations from their wild ancestors due to the effect of either genetic drift or selective pressures unintendedly imposed on the strain during insectary rearing. However, considering the limited time the strain was maintained in the laboratory prior to its release, we believe that any phenotypic variation caused by this process is likely to be limited and therefore should not significantly impact the results of the current work.

Furthermore, in spite of the high efficiency of the sexing process - estimated at $99.94 \%$ - it is impossible to rule out the unintended release of a minimal number of female individuals during the experiment. However, considering that (i) the species released is endemic to the study area, (ii) the strain released is of Panamanian origin and (iii) the number of released females is likely to be extremely low (14,388 specimens released, with $99.94 \%$ sexing accuracy, corresponds to $\sim 9$ females released in total), it was estimated that the potential risks for the population and environment in the study area were negligible. As previously stated, detailed knowledge of male mosquito biology is a crucial element for the design of genetic population control strategies which rely on the release of adult male transgenic individuals (Thomas et al. 2000, Phuc et al. 2007, Alphey et al. 2008, 2010, Harris et al. 2011, 2012). Even considering that the data generated by this study would have to be locally validated for transgenic strains of Ae. aegypti, they give encouraging insights for potential genetic control programs in the area: mean survival of two to three days would imply the need to perform releases of 10,000 males two-three times a week to maintain a 10:1 standing crop ratio of sterile to wild males in the environment. However, it should be considered that field studies in the Cayman Islands and Malaysia report a lower DSP for OX513A males (mean $\mathrm{DSP}=0.33$, equivalent to $\sim 0.9$ days) (Lacroix et al. 2012, Winskill et al. 2014). Taking this lower DSP reported for OX513A, a release of 25,000 males three times a week (for a total of 75,000 males/week) would be required to achieve a 10:1 ratio of OX513A:wild males in the study area. Furthermore, the larger size of insectary-reared specimens may prove advantageous since larger males have been reported to be more successful at mating with females, as well as carrying more spermatozoids (Ponlawat \& Harrington 2009).

\section{ACKNOWLEDGEMENTS}

To the inhabitants of the neighbourhood of Nuevo Chorillo, for providing us with access to their properties, to Dr Lyliana Diez and the personnel at the Nuevo Chorillo Health Centre, who were an invaluable source of local information, as well as proactive facilitators in establishing effective communication with the community, and to the researchers and staff at the Gorgas Institute, as well as the health authorities of the Republic of Panama, for their support for this study.

\section{REFERENCES}

Alphey L, Benedict M, Bellini R, Clark GG, Dame DA, Service MW, Dobson SL 2010. Sterile-insect methods for control of mosquitoborne diseases: an analysis. Vector Borne Zoonotic Dis 10: 295-311.

Alphey L, Nimmo D, O'Connell S, Alphey N 2008. Insect population suppression using engineered insects. In S Aksoy (ed.), Transgenesis and the management of vector-borne disease, Landes Bioscience/ Springer Science+Business Media, LLC, New York, p. 93-103.

Ansari MA, Singh KR, Brooks GD, Malhotra PR, Vaidyanathan V 1977. The development of procedures and techniques for mass rearing of Aedes aegypti. Indian J Med Res 65 (Suppl.): S91-S99.

Bailey NTJ 1951. On estimating the size of mobile populations from recapture data. Biometrika 38: 293-306

Bailey NTJ 1952. Improvements in the interpretation of recapture data. J Anim Ecol 21: 120-127.

Barrera R, Amador M, MacKay AJ 2011. Population dynamics of Aedes aegypti and dengue as influenced by weather and human behavior in San Juan, Puerto Rico. PLoS Negl Trop Dis 5: e1378.

Bhatt S, Gething PW, Brady OJ, Messina JP, Farlow AW, Moyes CL, Drake JM, Brownstein JS, Hoen AG, Sankoh O, Myers MF, George DB, Jaenisch T, Wint GR, Simmons CP, Scott TW, Farrar JJ, Hay SI 2013. The global distribution and burden of dengue. Nature 496: 504-507.

Buonaccorsi JP, Harrington LC, Edman JD 2003. Estimation and comparison of mosquito survival rates with release-recaptureremoval data. J Med Entomol 40: 6-17.

Cáceres L, Rovira J, Garcia A, Torres R, de la Cruz M 2013. Determinación de la sensibilidad a insecticidas organofosforados, carbamato y piretroides en poblaciones de Aedes aegypti Linneaus, 1762 (Díptera: Culicidae) de Panamá. Biomedica 33: 70-81. 
Camargo S 1967. History of Aedes aegypti eradication in the Americas. Bull World Health Organ 36: 602-603.

Christophers SR 1960. Aedes aegypti - the yellow fever mosquito: its life history, bionomics and structure, Cambridge University Press, Cambridge, 739 pp.

Conway GR, Trpis M, McClelland GAH 1974. Population parameters of the mosquito Aedes aegypti (L.) estimated by mark-release-recapture in a suburban habitat in Tanzania. J Anim Ecol 43: 289-304.

Dyck VA, Fernandez EER, Flores JR, Teruya T, Barnes B, Riera PG, Lindquist D, Reuben R 2005. Estimation of population density and mortality by mark-recapture experiments. In VA Dyck, J Hendrichs, AS Robinson, Sterile insect technique. Principles and practice in area-wide integrated pest management, Springer, Dordrecht, p. 183-192.

Fisher RA, Ford EB 1947. The spread of a gene in natural conditions in a colony of the moth Panaxia dominula L. Heredity (Edinb) 1: $143-174$.

Focks DA 1980. An improved separator for the developmental stages, sexes and species of mosquitoes (Diptera: Culicidae). J Med Entomol 17: 567-568.

Focks DA, Alexander N 2006. Multicountry study of Aedes aegypti pupal productivity survey methodology: findings and recommendations. Tropical disease research, WHO, Geneva, 48 pp.

Focks DA, Brenner RJ, Hayes J, Daniels E 2000. Transmission thresholds for dengue in terms of Aedes aegypti pupae per person with discussion of their utility in source reduction efforts. Am J Trop Med Hyg 62: 11-18.

Focks DA, Chadee DD 1997. Pupal survey: an epidemiologically significant surveillance method for Aedes aegypti: an example using data from Trinidad. Am J Trop Med Hyg 56: 159-167.

Focks DA, Sackett SR, Bailey DL, Dame DA 1981. Observations on container-breeding mosquitoes in New Orleans, Louisiana, with an estimate of the population density of Aedes aegypti (L.). Am J Trop Med Hyg 30: 1329-1335.

Hagler JR, Jackson CG 2001. Methods for marking insects: current techniques and future prospects. Annu Rev Entomol 46: 511-543.

Halstead SB 2012. Dengue vaccine development: a 75\% solution? Lancet 380: 1535-1536.

Harbach RE, Knight KL 1980. Taxonomist's glossary of mosquito anatomy, Plexus Publications, New Jersey, 415 pp.

Harrington LC, Scott TW, Lerdthusnee K, Coleman RC, Costero A, Clark GG, Jones JJ, Kitthawee S, Kittayapong P, Sithiprasasna R, Edman JD 2005. Dispersal of the dengue vector Aedes aegypti within and between rural communities. Am J Trop Med Hyg 72: 209-220.

Harris AF, McKemey AR, Nimmo D, Curtis Z, Black I, Morgan SA, Oviedo MN, Lacroix R, Naish N, Morrison NI, Collado A, Stevenson J, Scaife S, Dafa'alla T, Fu G, Phillips C, Miles A, Raduan N, Kelly N, Beech C, Donnelly CA, Petrie WD, Alphey L 2012. Successful suppression of a field mosquito population by sustained release of engineered male mosquitoes. Nat Biotechnol 30: 828-830.

Harris AF, Nimmo D, McKemey AR, Kelly N, Scaife S, Donnelly CA, Beech C, Petrie WD, Alphey L 2011. Field performance of engineered male mosquitoes. Nat Biotechnol 29: 1034-1037.

Jackson CHN 1939. The analysis of an animal population. J Anim Ecol 8: 238-246.

Johnson PH, Spitzauer V, Ritchie SA 2012. Field sampling rate of BGSentinel traps for Aedes aegypti (Diptera: Culicidae) in suburban Cairns, Australia. J Med Entomol 49: 29-34.

Jolly GM 1965. Explicit estimates from capture-recapture data with both death and immigration-stochastic model. Biometrika 52: 225-247.
Kröckel U, Rose A, Eiras A, Geier M 2006. New tools for surveillance of adult yellow fever mosquitoes: comparison of trap catches with human landing rates in an urban environment. J Am Mosq Control Assoc 22: 229-238.

Lacroix R, McKemey AR, Raduan N, Wee LK, Ming WH, Ney TG, Rahidah AAS, Salman S, Subramaniam S, Nordin O, Hanum ATN, Angamuthu C, Mansor SM, Lees RS, Naish N, Scaife S, Gray P, Labbe G, Beech C, Nimmo D, Alphey L, Vasan SS, Lim LH, Wasi AN, Murad S 2012. Open field release of genetically engineered sterile male Aedes aegypti in Malaysia. PLoS ONE 7: e42771.

Lincoln FC 1930. Calculating waterfowl abundance on the basis of banding returns. US Dept of Agriculture 118: 1-4.

Maciel-de-Freitas R, Codeço CT, Lourenço-de-Oliveira R 2007. Body size-associated survival and dispersal rates of Aedes aegypti in Rio de Janeiro. Med Vet Entomol 21: 284-292.

Maciel-de-Freitas R, Eiras AE, Lourenço-de-Oliveira R 2006. Field evaluation of effectiveness of the BG-Sentinel, a new trap for capturing adult Aedes aegypti (Diptera: Culicidae). Mem Inst Oswaldo Cruz 101: 321-325.

Manly BFJ, Parr MJ 1968. A new method of estimating the population size, survivorship and birth rate from capture-recapture data. Transactions of the Society for British Entomology 18: 81-89.

Muir LE, Kay BH 1998. Aedes aegypti survival and dispersal estimated by mark-release-recapture in northern Australia. Am J Trop Med Hyg 58: 277-282.

Nasci RS 1990. Relationship of wing length to adult dry weight in several mosquito species (Diptera: Culicidae). J Med Entomol 27: 716-719.

Niebylski ML, Craig Jr GB 1994. Dispersal and survival of Aedes albopictus at a scrap tire yard in Missouri. J Am Mosq Control Assoc 10: 339-343.

Papathanos PA, Bossin HC, Benedict MQ, Catteruccia F, Malcolm CA, Alphey L, Crisanti A 2009. Sex separation strategies: past experience and new approaches. Malar J 8 (Suppl. 2): S5.

Petersen CGJ 1896. The early immigration of young plaice into Limfjord from the German sea. Report of the Danish Biological Station 6: 5-84.

Phuc HK, Andreasen MH, Burton RS, Vass C, Epton MJ, Pape G, Fu G, Condon KC, Scaife S, Donnelly CA, Coleman PG, WhiteCooper H, Alphey L 2007. Late-acting dominant lethal genetic systems and mosquito control. BMC Biol 5: 11.

Ponlawat A, Harrington LC 2007. Age and body size influence male sperm capacity of the dengue vector Aedes aegypti (Diptera: $\mathrm{Cu}-$ licidae). J Med Entomol 44: 422-426.

Ponlawat A, Harrington LC 2009. Factors associated with male mating success of the dengue vector mosquito, Aedes aegypti. Am J Trop Med Hyg 80: 395-400.

Rendon P, McInnis D, Lance D, Stewart J 2004. Medfly (Diptera: Tephritidae) genetic sexing: large-scale field comparison of males-only and bisexual sterile fly releases in Guatemala. $J$ Econ Entomol 97: 1547-1553.

Reuben R, Yanuso M, Panicker KN, La Brecque GC 1973. The estimation of adult populations of Aedes aegypti at two localities in Delhi. J Commun Dis 5: 154-162.

Ritchie SA, Montgomery BL, Hoffmann AA 2013. Novel estimates of Aedes aegypti (Diptera: Culicidae) population size and adult survival based on Wolbachia releases. J Med Entomol 50: 624-631.

Sabchareon A, Wallace D, Sirivichayakul C, Limkittikul K, Chanthavanich P, Suvannadabba S, Jiwariyavej V, Dulyachai W, Pengsaa K, Wartel TA, Moureau A, Saville M, Bouckenooghe A, Vivi- 
ani S, Tornieporth NG, Lang J 2012. Protective efficacy of the recombinant, live-attenuated, CYD tetravalent dengue vaccine in Thai schoolchildren: a randomised, controlled Phase $2 \mathrm{~b}$ trial. Lancet 380: 1559-1567.

Schneider CA, Rasband WS, Eliceiri KW 2012. NIH image to ImageJ: 25 years of image analysis. Nat Methods 9: 671-675.

Seber GA 1965. A note on the multiple-recapture census. Biometrika 52: $249-259$.

Sheppard PM, Macdonald WW, Tonn RJ, Grab B 1969. The dynamics of an adult population of Aedes aegypti in relation to dengue haemorrhagic fever in Bangkok. J Anim Ecol 38: 661-702.

Thomas DD, Donnelly CA, Wood RJ, Alphey LS 2000. Insect population control using a dominant, repressible, lethal genetic system. Science 287: 2474-2476.

Trpis M, Häusermann W 1986. Dispersal and other population parameters of Aedes aegypti in an African village and their possible significance in epidemiology of vector-borne diseases. Am J Trop Med Hyg 35: 1263-1279.

Valerio L, Facchinelli L, Ramsey JM, Bond JG, Scott TW 2012. Dispersal of male Aedes aegypti in a coastal village in southern Mexico. Am J Trop Med Hyg 86: 665-676.
Vasconcelos PFC, Rosa APAT, Pinheiro FP, Rodrigues SG, Rosa EST, Cruz ACR, Rosa JFST 1999. Aedes aegypti, dengue and re-urbanization of yellow fever in Brazil and other South American countries - past and present situation and future perspectives. Dengue Bull 23: 55-66.

WHO/TDR 2006. Report of the Scientific Working Group Meeting on Dengue. Special Programme for Research and Training in Tropical Diseases, WHO, Geneva, 160 pp.

WHO/TDR 2009. Dengue: guidelines for diagnosis, treatment, prevention and control. Special Programme for Research and Training in Tropical Diseases, WHO, Geneva, 146 pp.

Williams CR, Long SA, Russell RC, Ritchie SA 2006. Field efficacy of the BG-Sentinel compared with CDC backpack aspirators and $\mathrm{CO}_{2}$-baited EVS traps for collection of adult Aedes aegypti in Cairns, Queensland, Australia. J Am Mosq Control Assoc 22: 296-300.

Winskill P, Harris AF, Morgan SA, Stevenson J, Raduan N, Alphey L, McKemey AR, Donnelly CA 2014. Genetic control of Aedes aegypti: data-driven modelling to assess the effect of releasing different life stages and the potential for long-term suppression. Parasit Vectors 7: 68.

Yamamura K, Wakamura S, Kozai S 1992. A method for population estimation from a single release experiment. Appl Entomol Zool 27: 9-17. 